\title{
DENTURE BIOFILM AND DENTUREASSOCIATED STOMATITIS, A LITERATURE REVIEW
}

\author{
Hanadi A. Lamfon ${ }^{*}$
}

\begin{abstract}
Denture stomatitis is increased dramatically in the recent years, particularly in denture wearers. It is a common inflammatory reaction with multifactorial etiology that usually appears in the oral cavity as an erythematous reaction on the oral mucosa extends to the limits of the maxillary denturebearing area. Candida albicans is regarded as the primary cause of denture-associated stomatitis owing to its high capability to adhere to oral tissues and denture surfaces in addition to biofilms formation. Candida species can interact with different microorganisms within the mouth resulting in a complex and mixed biofilm formation with an organized structure which is difficult to remove. The presence of bacteria in the acrylic biofilms resulted in increased pathogenicity and virulence of Candida biofilms making them more resistance to antifungal drugs. This article was introduced to highlight on the denture biofilm microbiota and its role in Candida albicans pathogenicity in addition to exploring the clinical manifestation, multifactorial etiology and management policies of Candida-associated denture stomatitis frequently faced in dental clinic. An online search of PubMed, Scopus, Science Direct, and Google Scholar was conducted using key words (Microbiota, Candida albicans, Denture stomatitis, Biofilm) from 1978 up to 2021. The management of denture stomatitis mainly depends on enhancement of oral hygiene processes, description of antifungal agents either topical or systemic, as well as disinfectants description. Recently, medical extracts that possess antimicrobial activity against oral pathogens was introduced as a safe and less side effects protocol for management of denture stomatitis.
\end{abstract}

KEY WORDS: Microbiota, Candida albicans, Denture stomatitis, Biofilm.

\section{INTRODUCTION}

\section{Oral Microbiota}

Many microenvironments in the oral cavity, display suitable surfaces for microbial colonization.
The oral biofilm develops not only on the enamel surfaces and soft tissues but similarly on the dental filling materials and prosthetic surfaces (Al-Ahmad et al, 2013).

* Associate Professor, Removable Prosthodontics, Faculty of Dentistry, Umm Al-Qura University, Makkah, Saudi Arabia. 
These oral biofilm has ability to originate many oral infectious diseases. Denture stomatitis is the most common infectious disease, plus dental caries and periodontal disease (Chapple et al, 2015, Figuero et al., 2017, Aoun and Berberi, 2017). Additionally the microorganisms forming biofilm colony may be disengaged from the old biofilm and transported to new places to reform a new biofilm. This transportation may initiate a metastatic infectious diseases as aspiration pneumonia as well as endocarditis (O'Donnell et al., 2015, Leoney et al., 2020).

On the other hand the microbiota resident in the oral cavity can prevent the progress of dental caries through decreasing levels of cariogenic bacteria by direct struggle for colonization (Wade et al., 2013, Kilian etal., 2016).

The healthy bacterial microbiota was characterized at tooth surfaces, oral mucosa and saliva indicating that more than 700 bacterial species are found within the oral cavity (Dewhirst et al., 2010, Acharya et al., 2017).

\section{Denture-Associated Biofilm Microbiota}

The concept of biofilm was utilized to characterize an entirely regular collection of microorganisms embedded in a specific matrix. This biofilm has ability to stick to animate or inanimate surfaces (Nett et al., 2010).

Biofilm formation on the denture base could be considered as the main cause of oral infections, mainly denture stomatitis. This disease affects from $30 \%$ to $75 \%$ of denture wearing patients (Pereiral et al., 2013). It appears as erythema in the palatal mucosa that directly contacts the fitting-surface of a partial or complete prosthesis.

Candida albicans has been pointed out as the main etiological factor of oral lesions. It is the strongest infectious pathogen among the other Candidal types. It is the most common type of Candida found in the oral cavity, it counts about 70 to $80 \%$ of the isolated microorganisma from the oral mucosal infections (Ribeiro, et al., 2012 a). It is an opportunistic pathogen, that is able to reversibly transform between yeast and elongated hyphae which is the pathogenic form (Santana et al., 2013).

Candida species can interact with different microorganisms within the mouth, such as Streptococcus species and Staphylococcus species, creating a hybrid and complex ordered assembly of biofilm construction which is difficultly removed inducing significant damage in tissues with a significant increase in the immune response when compared to Candida albicans biofilms. Thus, the presence of bacterial species within denture biofilms is essential in increasing pathogenicity and virulence of Candidal biofilms (Cavalcanti et al., 2015). Kashiwabara et al. in 2007 isolated high levels of Staphylococcus species and Candida species from fitting surface of upper prostheses in elderly patients and those with defect in the maxillary arch.

Based on the fact that, denture in its place in the oral cavity is adjacent to respiratory system, so denture wearer is high susceptible to aspirate opportunistic pathogens found in the denture into the respiratory system resulting in elevated rate of aspiration pneumonia (O'Donnell et al., 2015). In addition to pneumonia, oral microorganis play a role in bacterial endocarditis, gastrointestinal infection and chronic obstructive pulmonary disease. Denture acts as reservoir for pathogens related to these infections (Przybyłowska et al., 2015, Coulthwaite et al., 2007). Therefore, careful denture cleaning is mandatory to remove the oral bacterial and denture biofilms using suitable denture cleaning agents to avoid related oral and/or systemic diseases (Felton et al., 2011).

Based on clinical study that was conducted to evaluate the usage of next generation sequencing for characterization of denture-associated biofilms in patients with and without clinical manifestations of denture stomatitis. The purpose of the study was the characterization of species level with 
occurrence of disease. Genus-level information is very important because there are considerable differences existing among species with the same genera. In the oral cavity, Streptococcus salivarius and mutans are important examples of two distinct species found within the same genus, particularly in terms of pathogenicity and virulence. Streptococcus salivarius is considered a commensal bacterial species that are not normally associated with oral infection, while Streptococcus mutans is a known pathogen, associated with the development of dental caries (Morse et al., 2019).

The inter-kingdom collaborations among Streptococcusmutans and Candida albicans was revealed by Kim et al., in 2017. They found that the existence of Candida albicans rise the microcolonies establishments and ensuing virulence of Streptococcus mutans. They also concluded that the elevated quantity and virulence of an individual bacterial species can resulted in bad prognosis,

In non denture stomatitis cases (NoDS), Pseudomonas putida, A. lwoffii, Lactobacillus salivarius were decreased in number while A. lingnae showed a minimal reduction in (NoDS). It was also found that a unique for denture stomatitis, two of the three greatest plentiful bacterial species were isolated from denture base surface. These included an unknown species within the genus Myroides, and Pseudomonas fluorescens, with relative abundances of approximately $8.5 \%$ and $7.2 \%$, respectively. Furthermore, a greater increase in Brevundimonasvesicularis in NoDS cases compared with DS cases was evident. Conversely, there were a reduction of S. oralis, Chrysobacterium species, B. terrae and a slight decrease in A. johnsonii in NoDS cases.

Streptococcus salivarius taken from tongue swap was represented the highest relative abundance. However, a non-significant difference was detected between DS and NoDS patients. Significant difference was found in the quantity of P. fluorescens and S. mitis between DS and NoDS,
Slighter variation was detected with other bacterial species common between DS and NoDS patients, but the extent of the differences weren't so clear (Kim et al., 2017).

\section{Candida Albicans Denture Biofilm}

The formation of fungal biofilm is a complicated phenomenon that differs from adhesion (Chandra et al., 2001). Biofilm formation is a specific characteristic strain which greatly varies through Candida albicans and non-albicans. It has a critical part in infection insistence. (Hasan et al., 2009) The spatial complexity and heterogeneity found in the intact biofilms may be correlated to cell-cell connection and they are extremely arranged gene expression structures (Ramage et al., 2001).

The alterations in gene expression accompanying C.albicans biofilm growth were performed utilizing microarrays. The study suggests that the phenotype and morphology of C. albicans biofilm are regulated by genes belonging to interconnected different functional categories (Yeater et al., 2007).

Candidal biofilms have been revealed to contain a mixture of different types of cells as yeast, hyphal and pseudohyphal cells. They also contain an extracellular matrix consists of polysaccharide in addition to protein. (Branda, 2005, Blankenship and Mitchell, 2006) This biofilm matrix is formed by focused synthesis plus secretion of the matrix ingredients in addition to biofilm cells lysis (Nobile and Mitchell, 2007). It has a very essential role in biofilm creation. It provides a physical barrier that protects microorganisms from their surroundings, prevents the penetration of the biofilm by antimicrobial drugs and other stresses and also maintains the biofilm architecture stability so it acts as an adhesive holding the cells with one another (Nobile et al., 2009).

Suspended planktonic cells of C.albicans and biofilms synthesize extracellular prostaglandins at $37^{\circ} \mathrm{C}$ during growth however biofilm cells significantly secret more prostaglandins. It was 
suggested that prostaglandin may be an important virulence element in infections associated with biofilm, but its function in the morphogenesis of Candida albicans is still enigmatic (Alem and Douglas, 2005).

Biofilms of human Candida albicans can also grow on mucosal surfaces, populate and penetrate surfaces (Dongari-Bagtzoglou, 2008). This capability to penetrate the surfaces was considered as a virulence factor (Richard et al., 2005). C. albicans is able to reversibly convert from its yeast form into another hyphal form. This convertibility is considered as the main factor of its virulence (Alem et al., 2006).The origin and development of morphological characteristics of Candida albicans is controlled through a complex control via quorumsensing molecules work act (Chen et al., 2004).

Some environmental factors have been thought to be determinant factors induce Candida albicans hypha formations. Stimuli such as elevation of $\mathrm{pH}$ level and temperature, malnourishment and change in cell density are considered as hypha-inducing conditions (Ernst, 2000).

A relation between biofilm development and quorum sensing was verified in different bacterial species. The quorum-sensing molecule for biofilms and their role is critical in the initial and intermediate phases of biofilm creation (Alem et al., 2006).The alteration of surface properties of biomaterials affects Candida albicans capability to biofilms formation (Chandra et al., 2005).

The candida biofilms consistently secrete virulence attributes which is secreted aspartyl protease (Saps) more than their planktonic counterparts. (Mendes et al., 2007).

Candida biofilms are grown on substrate, such as catheter or denture, affects biofilm morphology plus its architecture. Biofilms of model denture which were allowed to grow on polymethylmethacrylate strips coated with saliva, mainly contains yeast forms with no distinct layers and are typically between twenty and thirty millimeters in thickness (Chandra et al., 2001a). On the other side, Candida biofilms which are allowed to grow on silicone elastomeric catheter discs coated with serum contains a basal layer of yeast cells covered by a layer of hyphae in the mature phase of growth. Model biofilms of catheter are typically two and three hundreds millimeters in thickness (Chandra et al., 2001a; Kuhn et al., 2002).

The matured Candida albicans biofilms are composed of a dense network of hyphal elements and yeasts cells embedded in exopolymeric material. Candida albicans biofilms have a complex 3D structure with a typical architecture and spatial heterogeneity appearing like microcolonies with branching water ducts (Ramage et al., 2001). It has been shown that biofilm formation proceeds through three distinct phases of development. The formation and development of candida biofilm continue in a systematic manner through the early, intermediate and maturation stages of formation. These stages transform adherent blastospores to well defined cellular communities embedded in a polysaccharide matrix. Candida biofilms, which are being developed, are correlated with the rising attendance of extracellular material (Chandra et al., 2001).

Finally, it is concluded that numerous factors decide Candida harboring biofilms. These factors comprise micro-organisms interactions, saliva, surface properties and the architecture of biofilm. (Pereira-Cenci et al., 2008). In addition to that cell to cell communication of microbes has a critical function in the process of colonization. Microorganisms found in the oral cavity interact with each other in different ways, by communicating more directly through signaling molecules or using metabolic end-products of each other (Blankenship and Mitchell, 2006). 


\section{Denture Stomatitis}

Denture stomatitis exists as the commonest type of candidal oral infection affecting palatal mucosa of denture wearer (30-75\%). Candida albicans is the most predominant species, found in fifty to ninety eight percentages of all cases (Baena-Monroy et al.,2005, Salles et al., 2015).

Denture stomatitis appears in the oral cavity as an erythematous reaction on the oral mucosa beneath the maxillary denture (Aoun and Berberi, 2017) accompanied with burning, pain and change in taste feeling. Candida albicans, which is pointed out as the main etiologic microrganism, that isolated from both denture inner surface and mucosa beneath it (Martin and lamb, 1982). Denture associated stomatitis may appear in there different clinical categories: Type one, presents as localized inflammation and often as pinpoint hyperaemia. Type two, presents as diffuse erythema. Type three, presents as diffuse inflammation and papillary hyperplasia (Budtz-Jorgensen, 1978).

Denture stomatitis having many predisposing agents that can be classified into systemic and local factors. Denture trauma, continuous denture wearing, poor denture hygiene, materials of the denture base, diminished salivary flow, smoking habits, and microbiota changes of the mouth is considered as the main local factors of disease emergence (Coco et al., 2008, Gasparoto et al., 2009). While systemic factors include denture wearers immunity, antibiotics, recurrent infection, systemic steroids, endocrine diseases and age (Budtz-Jörgensen, 1990).

Furthermore, denture biofilm is considered as the most significant etiologic cause that trigger DS. Where the denture existence may produce a local alterations of the oral condition that may enhance the proliferation of normally commensal microbiota into pathogenic form. The denture acts as a reservoir for opportunistic microorganisms that cause the disease (André et al., 2011, O'Donnell et al., 2015). Moreover, the reduced manual dexterity of elderly peoples as well as the elevated count of immunocompromised cases elevate the liability of the aged patients to various infectious diseases of the oral mucosa (Coenye et al., 2011).

\section{Management of Denture Stomatitis}

Because of the denture stomatitis has multifactorial causes with many cases relapse, so its management is a challenge. The recommended treatment strategy of DS mainly based on; removing of predisposing agents.(Martins and Gontijo, 2017) enhancement of oral hygiene procedures (Hasan et al., 2015), description of antifungal agents either topical or systemic, as well as disinfectants description (Hilgert et al., 2016). Slow release antifungal/ antimicrobial agents may be also incorporated into denture base materials (Bueno et al 2013).

Denture cleaning and disinfection are importantly advised as the first aids in disease control. However failure of obtaining a proper denture hygiene share in recurrence of the disease even a proper treatment protocol was allowed. (Martins and Gontijo, 2017). Nevertheless, the efficiency of trading denture cleaning agents in fungi elimination still questionable (Felton et al., 2011).

\section{Denture Cleaning and Hygiene}

Although manual brushing method of dentures is represented as the most commonly used cleaning habit, (Papadiochou , Polyzois, 2018) it alone was regarded as one of the least efficient methods used to prevent and control denture biofilm. (Paranhos et al.,2013). Adding dentifrice exhibited better results compared to brushing with neutral soap (Paranhos et al.,2013).

The manual brushing method requires visual acuity and manual dexterity that are compromised in denture wearers (Neppelenbroeket al., 2008). Furthermore, the micro-porosities and irregularities of acrylic denture bases enhance microorganisms penetrating ability, making it difficult to clean them via brushing only. Hence denture may be appointed as 
the origin of infection and re-infection for the denture bearing area (Neppelenbroeket al., 2008, Baena-Monroy et al., 2005). Thus ultrasound cleaning was advised as an alternative cleaning method to denture wearers with difficulty in performing manual brushing. But it must be noticed that ultrasonic cleaning methods only with distilled water not enough to remove denture biofilm it should be immersed in a chemical solution. (Nishi et al., 2014)

Daily immersion of dentures within cleaning mixture was advised in order to improve denture hygiene. Such cleaning mixture presented better outcomes in comparison with the brushing only (Lucena-Ferreira et al., 2014).

Many commercial denture cleaning agents are obtainable accompanied by various active ingredients, such as peroxides, hypochlorite, acids and enzymes. Homemade solutions are used by complete or partial denture patients to perform chemical cleaning of denture due to low cost and their easy of gaining. $0.5 \%$ sodium hypochlorite, $0.2 \%$ digluconate chlorhexidine, and alkaline peroxide solutions approved as the best chemical cleaning agents allowing reduction in the total microbial counts. (Srinivasan, Gulabani, 2010, Duyck et al., 2013, de Sousa Porta et al., 2015).

Because sodium hypochlorite is able to dissolve mucin and other organic ingredients, it is the chemical solution of choice that is routinely used for denture cleaning. It is highly efficient at cleaning light stains. It has also bactericidal and fungicide action. (Felton et al., 2011) on the other hand, many drawbacks of using sodium hypochlorite solution as denture cleanser have been found as it corrodes metallic dentures parts also it has ability to worsen component parts of acrylic resin resulting in color alterations of acrylic resin as well as surface roughness (Felton et al., 2011,Neppelenbroek et al., 2015).

Chlorhexidine is commonly used chemical agent due to its ability to prevent and treat many of oral infections. It was recommended as disinfectants and antiseptics for removable dentures. Chlorhexidine gluconate has significant substantively and wide spectrum of action, so it was utilized efficiently where mixed fungal and bacterial biofilms are existing. It has also been suggested in a high concentration $2 \%$ as an alternative denture cleaner instead of brushing as an overnight disinfecting agent (Ellepola and Samaranayake, 2000, Banting et al., 2001, Kashiwabara., et al., 2007).

There are also commercial denture cleaning agents used as alkaline peroxides. It produces hydrogen peroxide as an alkaline fizzy solution, having active oxygen, once becomes on touch to water. The effervescent action removes debris by mechanical act while the oxygen has stain-removing action and antimicrobial action. There are other products that have enzymes that destroy biofilm proteins (Lucena-Ferreira et al., 2014).

Other alternatives to familiar denture cleaning agents have been used. Products with antimicrobial effect have been developed like Ricinus communis, which is an oil derived from castor bean. It has bactericidal and fungicidal effects with great degree of biocompatibility. It is colorless without an unpleasant smell, so with its detergent action, it might be used as an alternative denture cleanser (Salles, et al., 2015).

Due to the constant concern about controlling biofilm, many studies have been carried out to compare and assess the efficacy of different denture cleaning methods (Lucena-Ferreira et al., 2014)

The combined method ofmechanical and chemical cleansers exists as the best manner for Candidal biofilm removal. Pellizzaro, et al., 2012 found that $1 \%$ sodium hypochlorite and $2 \%$ chlorhexidine gluconate are the most effective solutions. While de Sousa Porta et al., 2015 concluded that the combination of brushing method and $0.5 \%$ sodium hypochlorite produces highly satisfied cleaning outcomes and efficient in decreasing numbers of microorganism without producing roughness or remarkable color alterations. 
However, Lucena-Ferreira et al., 2014 found that the use of alkaline peroxide enzyme denture cleaning agent, in-vitro, for three minutes daily decreased total number of bacterial microorganisms, on the other hand Candida albicans number elevated. Accordingly, the regular use of it will control bacterial biofilm. However the Candida albicans is the main cause of oral candidiasis.

$0.5 \%$ sodium hypochlorite solution was recommended by Salles et al., 2015 as an effective method to decrease denture biofilm when immersed for short period.

The significance of denture cleaning protocol before overnight storing was clarified to decrease the C. albicans establishment. If the possibilities of dentures cleaning was difficulties and the cleaning tablet is not available, the overnight dry storing is advised to reduce $\mathrm{C}$. albicans settlement, with insignificant dimensional changes of the prosthesis. Where dentures storing in water alone enhance C. albicans colonization. (Verhaeghe et al., 2020).

Recently, photodynamic therapy was emerged as a novel method of prostheses disinfection with $90 \%$ reduction of microbial counts. The mechanism of disinfection of this technique depends on using a special light source to activate a photosensitizer that induce certain reactions that allow cell death (Ribeiro et al., 2012, Cinzia et al., 2018).

As a conclusion, the regular oral cleanliness habit, including brushing or ultrasound vibration along with chemical cleaning agents, are important factors assure daily meticulous elimination of oral as well as denture biofilms. This cleaning protocol is advised to decrease opportunistic infections, achieve satisfactory oral hygiene, preserve odors-free and esthetically acceptable prosthesis (Neppelenbroek, 2015, Papadiochou and Polyzois, 2018).

\section{Antifungal Medications}

The particular antifungal medications like amphotericin B, nystatin, miconazole or clotrimazole are described either locally or systemically to stop the disease development (Walsh et al., 2015). Topical or systemic conventional antifungal agents as Fluconazole and nystatin may be used for treatment of DS (Bueno et al., 2017) because of their elevated oral bioavailability as well as their simple reach (Singh et al., 2017).

On the other hand, the ineffective action of these drugs on the fitting surface of the infected dentures moreover the biofilm resistance are considered the main limitations of this line of treatment (Bueno et al., 2017). The Candida biofilm resistance to antimicotic drugs may be attributed to physical barrier performed by biofilm matrix. This barrier provide a delayed and inadequate diffusion of antimicrobial drugs inside the biofilm. Consequentially a unique and more preserved phenotypic form was developed adding difficulty to disease control (Samaranayake, et al., 2009).

In addition to the above mentioned drawbacks, nausea due to their unlikable taste, diarrhoea and allergic responses is appeared with the topical antifungal agents use (Walsh et al., 2015). As well the systemic antifungal agents have unwanted side effects as nephrotoxicity (Varlam et al., 2001) and hepatotoxicity In prolonged protocols (Heinemann et al., 1997).

Bueno et al., 2017 added that, diluent effect of saliva salivary flow makes the maintenance of an effective topical medication concentration at the contaminated surfaces and tissues is hard. Beside the swallowing action and the tongue movements quickly eliminate and dissolve the drug from the applied area (Zhang et al., 2020).

\section{Recent Antimicrobial Alternatives}

In recent years, many researches were worked on providing an alternative sources for management of denture stomatitis extracted from natural products. As it was also found that some herbal extracts possess antimicrobial activity antagonistic toward oral pathogens especially Candida albicans with 
safe and less drawbacks. (Endo et al., 2010, Labsi et al., 2016, Zainal et al., 2020).

Allicin is one of the herbal extracts that has a powerful antimicrobial properties against Staff aureus and Candida albicans, thus it was considered as a promising substitute for treatment of DS. Also, it has capability to eliminate denture biofilm after short exposure so it can be added to denture cleaners as active ingredients (Zainal et al., 2020).

Punica granatum L, another herbal extract has been studied for its antimicrobial effect by Bakkiyaraj et al. 2013 and Labsi et al. 2016. The raw extractor from Punica granatum is able to prevent microbial sticking. It has been suggested that C. albicans and oral bacterial biofilms were responsive to it. So, these plant herbal extracts may perform a critical role in the prevention and / or treatment of denture stomatitis (Alavarce et al., 2015). Thus, more attention was exerted to detect these extract (Anibal et al., 2013).

Denture adhesives that recommended to complete denture wearers specially the maxillary one to improve the masticatory efficiency and patient satisfaction by enhancing the retention of the prosthesis (Bartlett et al. 2013). Also the usage of the adhesive allows wide distribution of the masticatory forces on all denture bearing areas, this will result in minimizing tissue irritation and decreasing the possibility of emerging denture stomatitis (Papadiochou et al., 2015). These adhesives possess antimicrobial ingredients like sodium tetra borate, hexachlorophene, sodium borate plus ethanol (Grasso, 2004, Pradies et al., 2009). Thus, the continuous apply of these adhesives biocompatible materials linked with medications that have anti Candida effect may be very effective for prevention of denture stomatitis or may aid in the treatment of it.

Almeida et al., 2018 also concluded that P. granatum extracts and $\mathrm{E}$. giganteum in combination with COREGAR reduced the progress of Candida biofilms on the acrylic resin surface by reducing their colonization and metabolism. It played a innovative and synergistic role as a temporary material which may help in the prevention and treatment of denture stomatitis.

Based on the conclusions of an in vitro study of Namangkalaku et al., 2020, chitosan could be established as an antifungal denture adhesive for preventing and management of denture stomatitis. Also Chitosan has many promising characteristics, as, Chitosan was approved as broad-spectrum antimicrobial activity anti fungi in addition to bacteria. As Chitosan has ability to disrupt cell membrane of microorganism and providing an intracellular outflow of ions and inhibit (DNA), (RNA), and protein production (Sahariah, Masson, 2017, Verlee et al., 2017). Moreover, chitosan has ability to inhibit Candida adherence to denture thus prompt antifungal drug resistance. Added to the above mentioned advantageous, chitosan can help in preserving mucosal integrity and healing process (Singh et al., 2017). Thus, chitosan is biocompatible and biodegradable material, in combination with nystatin mouthwash can improve the clinical feature of denture stomatitis with no adverse effects; therefore, it could be used as an alternative to the currently available antifungal therapy using nystatin alone (Dash et al., 2011).

Also, combination of Indocyanine green dye -mediated Photodynamic therapy with nystatin mouthwash can help in treatment of denture stomatitis than using nystatin alone with no side effects (Afroozia et al., 2019).

Alcohol-free chitosan-curcuminoid mouthwash possibly provide an effective and safe topical applicant substitute for management of denture stomatitis (Mustafa et al., 2019).

Another promising mode of DS treatment using probiotic straining Streptococcus salivarius K12 to counteract Candidal colonization in acrylic dentures was provided by Ishikawa et al., 2014, Labsi et al., 2016, Passariello et al., 2020. 
Incorporation of nanoparticle metal oxides into acrylic denture bases provide antimicrobial effects against C. albicans and other microorganisms of denture biofilm. (Ahmad et al., 2020). This nano toxicity could be due to direct attack of nanoparticles to fungal cell membrane causing cell death. Takamiya et al., 2021 proved that the addition of $0.5 \%$ of nanoparticles SNP into PMMA resin is considered biocompatible providing antimicrobial actions against $\mathrm{C}$. albicans biofilm with no interference with the flexural strength of the material.

Alves et al., 2020 used PDZ-mediated aPDT to treat DS. Their concluded that this method allows reduction of Candidal counts by reduction of the oral bacteria activity as well as antifungal activity and improvement the oral lesions. So they considered it as a promising treatment option help in reducing the total microbiota located in the palatal area of the patient and denture in cases of DS.

Miswak stick was introduced as an alternative safe natural method of denture and oral cares for completely edentulous patients. Also it may help in management of mild and moderate denture stomatitis as it has an antifungal and antibacterial impact in addition to encourage bone formation (Aboul Enein,2014, Bayaty et al., 2018, Mohamed et al., 2020).

\section{CONCLUSIONS}

On the basis of this review of literature, it may be concluded that the responsibility of multi-species biofilms in the emergency of denture stomatitis was explored by many current studies. Thus explanation of biofilm adhesion to different surfaces as well as its prevention is become mandatory.

The initial C. species adhesion to the materials is affected by their surface roughness as well as their free energy, so clinical studies that assess these properties is essential. Therefore the current studies have to work on production of a healthy materials that favor health condition and diminish recolonization by different microorganisms. The correlation between denture base material and its influence on microbial growing needs more clinical and epidemiological researches.

The cell-cell communication and greatly controlled gene expression organizations is responsible for the complexity of biofilm. Grasping alteration in gene expression, accompanying biofilm development on denture and catheter surfaces, allow utilizing of these simulations for checking of possible inhibitors of biofilm development.

Because of the denture stomatitis has multifactorial causes with many cases relapse, so its management is a challenge. The recommended treatment strategy of denture stomatitis mainly depends on enhancement of oral hygiene processes, description of antifungal agents either topical or systemic, as well as disinfectants description. The antifungal resistance of biofilm is also attributed to many other factors. Thus, recent researches by newer molecular biology tools have to work on the undiscovered features of the antifungal resistance of Candida biofilms.

The microorganisms forming biofilm colony may initiate a metastatic infectious diseases as aspiration pneumonia and endocarditis. These diseases are hardy to treated with the conventional antibacterial agents.

Considering the antibacterial activity of some plant extracts, thus many attention and further studies should be given to these medical extracts to evaluate their natural antiplaque effects.

\section{REFERENCES}

- Aboul Enein BH. The Miswak (Salvadora Persica) Chewing Stick: Cultural Implications in Oral Health Promotion. Saudi J Dental Research 5 (2014) 9-13.

- AcharyaA, Chan Y, Kheur S, Jin LJ, Watt RM, Mattheos N.Salivary microbiome in non-oral disease: A summary of evidence and commentary. Arch Oral Biol. 83 (2017) 169-173.

- Afroozia B, Zomorodianb K, Lavaeed F, Shahrabadie Z, Mardani M. Comparison of the efficacy of indocyanine 
green-mediated photodynamic therapy and nystatin therapy in treatment of denture stomatitis. Photodiagnosis and Photodynamic Therapy 27 (2019) 193-197.

- $\quad$ Ahmad N, Jafri Z, Khan ZH. Evaluation of nanomaterials to prevent oral Candidiasis in PMMA based denture wearing patients. A systematic analysis. Journal of Oral Biology and Craniofacial Research 10 (2020) 189-193.

- Al-Ahmad A, Wiedmann-Al-Ahmad M, Fackler A, Follo M, Hellwig E, $B €$ achle $M$, et al. In vivo study of the initial bacterial adhesion on different implant materials. Arch Oral Biol 58 (2013).

- Alavarce RA, Saldanha LL, Almeida NL, Porto VC, DokkedalAL, Lara VS. The beneficial effect of Equisetum giganteum L. against Candidabiofilm formation: new approaches to denture stomatitis. Evid Based Complement. Alternat Med (2015).

- $\quad$ Alem MA, Douglas LJ. Prostaglandin production during growth of Candida albicansbiofilms.J Med Microbiol 54 (2005)1001-5.

- $\quad$ Alem MA, Oteef MD, Flowers TH, Douglas LJ. Production of tyrosol by Candida albicans biofilms and its role in quorum sensing and biofilm development. Eukaryot Cell 5 (2006) 1770-9.

- $\quad$ Almeida NLM, Saldanha LL, da Silva RA, Pinke KH, da Costa EF, Porto VC, DokkedalAL, Lara VS Antimicrobial activity of denture adhesive associated with Equisetum giganteum-and Punica granatumenriched fractions against Candida albicans biofilms on acrylic resin surfaces. Biofouling 34 (2018) 62-73.

- Alves F, Carmello JC, Alonso JC, Mima EG, Bagnato VS,' Pavarina AC. A randomized clinical trial evaluating Photodithazine-mediated Antimicrobial Photodynamic Therapy as a treatment for Denture stomatitis Photodiagnosis and Photodynamic Therapy 32 (2020) 102041.

- André RF, Andrade IM, Silva-Lovato CH, Paranhos HF, Pimenta FC, Ito IY. Prevalence of mutans streptococci isolated from complete dentures and their susceptibility to mouthrinses. Braz Dent J 22 (2011) 62-7.

- Anibal PC, Peixoto IT, Foglio MA, Hofling JF. Antifungal activity of the ethanolic extracts of Punicagranatum L. and evaluation of the morphological and structural modifications of its compounds upon the cells of Candida 2013.

- Aoun G, Berberi A. Prevalence of chronic erythematous candidiasis in lebanese denture wearers: a clinico-microbiological study. Materia Socio-Medica 29 (2017) 26-29.

- Baena-Monroy T, Moreno-Maldonado V, Franco-Martínez F, Aldape-Barrios B, Quindós G, Sánchez-Vargas LO. Candida albicans, Staphylococcus aureus and Streptococcus mutans colonization in patients wearing dental prosthesis. Med Oral Patol Oral Cir Bucal 10 (2005) 27-39.
- $\quad$ Bakkiyaraj D, Nandhini JR, Malathy B, Pandian SK. The anti-biofilm potential of pomegranate (Punicagranatum L.) extract against human bacterial and fungal pathogens. Biofouling 29 (2013) 929-937.

- $\quad$ Banting DW, Hill SA. Microwave disinfection of dentures for the treatment of oral candidiasis. Spec Care Dentist 21 (2001) 4-8.

- $\quad$ Bartlett DW, Maggio B, Targett D, Fenlon MR, Thomas J.A preliminary investigation into the use of dentureadhesives combined with dietary advice to improve diets in complete denture wearers. J Dentistry 41(2013) 143-147.

- $\quad$ Bayaty FH, Zaidi WI, Abdullah MN, Emad O, Mazen M. AlObaidi J. Effect of Salvadora Persica (Miswak) on Alveolar Bone Healing after Tooth Extraction in Rat. Journal of International Dental and Medical Research 11 (2018) 770- 777).

- Blankenship JR, Mitchell AP.How to build a biofilm: a fungal perspective.CurrOpinMicrobiol 9 (2006) 588-594.

- Branda SS, Vik S, Friedman L, Kolter R. Biofilms: the matrix revisited.Trends Microbiol 13 (2005) 20-26.

- Budtz-Jorgensen E. Clinical aspects of Candida infection in denture wearers. JDent Assoc 96 (1978) 474-9.

- Bueno M, Urban V, Barbério G, Da Silva WJ, Porto V, Pinto L, Neppelenbroek K. Effect of antimicrobial agents incorporated into resilient denture relines on the Candida albicans biofilm. Oral Dis 21(2013) 57-65.

- Bueno MG, Urban VM, Barberio GS, da Silva WJ, Porto VC, Pinto L, Ng SM, Yap YY, Cheong JW, Ng FM, Lau QY, Barkham T, Teo JW, Hill J, Chia CS.Antifungal peptides: a potential new class of antifungals for treating vulvovaginal candidiasis caused by fluconazole-resistant Candida albicans. J Pept Sci 23 (2017) 15-221.

- Cavalcanti YW, Morse DJ, da Silva WJ, Del-Bel-Cury AA, Wei X, Wilson M, Milward P, Lewis M, Bradshaw D, Williams DW. Virulence and pathogenicity of Candida albicans is enhanced in biofilms containing oral bacteria. Biofouling 31 (2015) 27-38.

- Chandra J, Kuhn DM, Mukherjee PK, Hoyer LL, McCormick T, GhannoumMA. Biofilm Formation by the Fungal Pathogen Candida albicans: Development, Architecture, and Drug Resistance.J Bacteriol 183 (2001) 5385-5394.

- Chandra J, Mukherjee PK, Leidich S D, Faddoul FF, Hoyer LL, Douglas LJ, Ghannoum MA. Antifungal resistance of candidal biofilms formed on denture acrylic in vitro. $\mathrm{J}$ Dent Res 80 (2001 a) 903-908.

- Chandra J, Patel JD, Li J, Zhou G, Mukherjee PK, McCormick TS, Anderson JM, Ghannoum MA.Modification of surface properties of biomaterials influences the ability of Candida albicans to form biofilms. Appl Environ Microbiol 12 (2005) 8795-801. 
- $\quad$ Chapple IL, Van der Weijden F, Doerfer C, Herrera D, Shapira L, Polak D, et al Primary prevention of periodontitis: managing gingivitis. J Clin Periodontol 42 (2015).

- Chen HM, Fujita Q, Feng J, Clardy GR, Fink Tyrosol is a quorum sensing molecule in Candida albicans. Proc. Natl. Acad. Sci. USA 101 (2004) 5048-5052.

- Cinzia C, Fanuli M, Viganò L, Photodynamic therapy for oral candidosis: a new option? Juniper Online J Case Stud. 6 (2018) 1-3.

- Coco BJ, Bagg J, Cross LJ, Jose A,Cross J, Ramage G. Mixed Candida albicans and Candida glabrata populations associated with the pathogenesis of denture stomatitis. Oral Microbiol. Immunol. 23 (2008) 377-383.

- Coenye T, KD Prijck H, Nailis, H.J. Nelis, Prevention of Candida albicans biofilm formation, Open Mycol. J. 5 (2011) 9-20.

- Coulthwaite L, Verran J. Potential pathogenic aspects of denture plaque. Br J Biomed Sci. 64 (2007)180-9.

- Dash M, Chiellini F, Ottenbrite RM, Chiellini E. Chitosanea versatile semisynthetic polymer in biomedical applications. Prog Polym Sci36 ( 2011) 981-1014.

- de Sousa Porta SR, Lucena-Ferreira SC, Silva WJ, Del BelCury AA. Evaluation of sodium hypochlorite as a denture cleanser: a clinical study. Gerodontology. 32 (2015) 260-6.

- Dewhirst, F. et al. The human oral microbiome. Journal of Bacteriology 192 (2010) 5002-5017.

- Dongari-Bagtzoglou A. Pathogenesis of mucosal biofilm infections: challengesand progress.Expert Rev Anti Infect Ther. 6 (2008) 201-8.

- Duyck J, Vandamme K, Muller P, Teughels W. Overnight storage of removable dentures in alkaline peroxide-based tablets affects biofilm mass and composition. J Dent. 41 (2013) 281-1289.

- Ellepola AN, Samaranayake LP. Antimycotic agents in oral candidosis: an overview: 1. Clinical variants. Dental Update. 3 (2000) 111-116.

- Endo EH, Cortez DA, Ueda-Nakamura T, Nakamura CV,Dias Filho BP. Potent antifungal activity of extractsand pure compound isolated from pomegranate peels andsynergism with fluconazole against Candida albicans. ResMicrobiol. 161 (2010) 534-540.

- $\quad$ Ernst JF. Transcription factors in Candida albicans: environmental control of morphogenesis. Microbiology. 146 (2000) 1763-1774.

- Felton D, Cooper L, Duqum I, Minsley G, Guckes A, Haug S, Meredith P, Solie C, Avery D, Deal Chandler $\mathrm{N}$; Evidence-based guidelines for the care and mainte- nance of complete dentures: a publication of the American College of Prosthodontists. J Prosthodont. 20 (2011).

- Figuero E, Nobrega DF, García-Gargallo M, Tenuta LM, Herrera D, Carvalho JC. Mechanical and chemical plaque control in the simultaneous management of gingivitis and caries: a systematic review. J Clin Periodontol 44 (2017).

- Gasparoto TH, Dionı́ sio TJ, de Oliveira CE, Porto VC, Gelani V, Santos CF, Campanelli AP, Lara VS. Isolation of Candida dubliniensis from denture wearers. J. Med. Microbiol. 58 (2009) 959-962.

- Grasso JE. Denture adhesives. Dent Clin North Am.48 (2004) 721-733.

- Hasan S, Kuldeep, Shamimul H. Denture Stomatitis: A Literature Review. J. Orofac. Health Sci. 6 (2015) 65.

- HasanF, XessI, WangX, JainN, Friesb. Biofilm formation in clinical Candida isolates and its association with virulence. Microbes Infect. 11 (2009) 753-761.

- Heinemann V, Bosse D, Jehn U, Debus A, Wachholz K, ForstH, Wilmanns W.. Enhanced pulmonary accumulationof liposomal amphotericin B (AmBisome) in acute livertransplant failure. J AntimicrobChemother. 40 (1997) 295-297.

- Hilgert JB, Giordani JMDA, De Souza RF, Wendland EM, D'Avila OP, Hugo FN. Interventions for the management of denture stomatitis: A Systematic Review and MetaAnalysis. J. Am. Geriatr. Soc. 64 (2016) 2539-2545.

- Ishikawa K, Mayer MPA, Miyazima TY, Matsubara VH, Silva EG, Paula CR, Campos TT, Nakamae AA. Multispecies Probiotic Reduces Oral Candida Colonization in Denture Wearers. J. Prosthodont. 24 (2014) 194-199.

- Kashiwabara T, Yoshijima Y, Hongama S, Nagao K, Hirota K, Ichikawa:Denture Plaque Microflora in Geriatric Inpatients and Maxillary Defect Patients. Prosthodont Res Pract.6 (2007)153-8.

- Kilian M, Chapple ILC, Hannig M. The oral microbiomean update for oral healthcare professionals. British Dental Journal 221 (2016) 657-666.

- $\quad$ Kim D, Sengupta A, Niepa TH, Lee BH, Weljie A, Freitas-Blanco VS, Murata RM, Stebe KJ, Lee D, Koo H. Candida albicans stimulates Streptococcus mutansmicrocolony development via cross-kingdom biofilm-derived metabolites. Sci Rep. 30 (2017) 7:41332.

- Kuhn DM, George T, Chandra J, Mukherjee PK, Ghannoum MA. Antifungal susceptibility of Candida biofilms: unique efficacy of amphotericin B lipid formulations and echinocandins. Antimicrob Agents Chemother. 46 (2002)1773-80. 
- $\quad$ Labsi M, Khelifi L, Mezioug D, Soufli I, Touil-Boukoffa C.Antihydatic and immunomodulatory effects ofPunicagranatum peel aqueous extract in a murine modelof echinococcosis. Asian Pac J Trop Med. 9 (2016) 211-220.

- Leoney A, Karthigeyan S, Asharaf AS, Felix AJ. Detection and Categorization of Biofilm-forming Staphylococcus aureus, Viridans streptococcus, Klebsiella pneumoniae, and Escherichia coli Isolated from Complete Denture Patients and Visualization Using Scanning Electron Microscopy. Journal of International Society of Preventive and Community Dentistry. 10 (2020).

- $\quad$ Lucena-Ferreira SC, Ricomini-Filho AP, Silva WJ, Cury JA, Cury AA. Influence of daily immersion in denture cleanser on multispecies biofilm. Clin Oral Investig. 18 (2014) 2179-85.

- Martin MV, Lamb DJ. Frequency of Candida albicans serotypes in patients with denture-induced stomatitis and in normal denture wearers. J ClinPathol. 35 (1982) 888-91.

- Martins KV, Gontijo SMDL. Treatment of denture stomatitis: literature review. Revista Brasileira De Odontologia. 74 (2017) 215-220

- Mendes A, Mores AU, Carvalho AP, Rosa RT, Samaranayake LP, Rosa EA.Candida albicans biofilms produce more secreted aspartyl protease than the planktonic cells. Biol Pharm Bull. 30 (2007)1813-5.

- Mohamed N, Yacob N, Ali W, Ali A, Ismail N, Nasseri N. Miswak (Salvadora Persica) As an Alternative Oral Aid to Reduce Denture Induce Stomatitis on Edentulous Patients. J Int Dent Med Res 13 (2020) 639-645.

- Morse DJ, Smith A, Wilson MJ, Marsh L, White L, Posso R, Bradshaw DJ, Wei X, Lewis MAO, Williams DW: Molecular community profiling of the bacterial microbiota associated with denture-related stomatitis. Sci Rep.15 (2019)10228.

- Mustafa MW, Ungphaiboon S, Phadoongsombut, N, Chelae S, Mahattanadul S. effectiveness of an AlcoholFree Chitosan-Curcuminoid Mouthwash Compared with Chlorhexidine Mouthwash in Denture Stomatitis Treatment: A Randomized Trial. Journal of Alternative \& Complementary Medicine 25 (2019) 552-558

- Namangkalakul W, Benjavongkulchai S, Pochana T, Promchai A, Satitviboon W, Howattanapanich S, Phuprasong R, Ungvijanpunya N, Supakanjanakanti D, Chaitrakoonthong T, Muangsawat S, Thanyasrisung P, Matangkasombut O. Activity of chitosan antifungal denture adhesive against common Candida species and Candida albicans adherence on denture base acrylic resin. J Prosthet Dent (2020)123:181.
- Neppelenbroek KH, Kurokawa LA, Procópio AL, Pegoraro TA, Hotta J, Mello Lima JF, et al. Hardness and surface roughness of enamel and base layers of resin denture teeth after long-term repeated chemical disinfection. J Contemp Dent Pract.16 (2015) 54-60.

- Neppelenbroek KH, Pavarina AC, PalomariSpolidorio DM, SgavioliMassucato EM, Spolidorio LC, Vergani CE. Effectiveness of microwave disinfection of complete dentures on the treatment of Candida-related denture stomatitis. J Oral Rehabil. 35 (2008) 836-46.

- Neppelenbroek KH. The importance of daily removal of the denture biofilm for oral and systemic diseases prevention.J Appl Oral Sci. 23 (2015) 547-548.

- Nett JE, Marchillo K, Spiegel CA, Andes DR. Development and validation of an in vivo Candida albicans biofilm denture model. Infect Immun. 78 (2010) 3650-9.

- $\quad$ Nishi Y, Seto K, Kamashita Y, Kaji A, Kurono A, Nagaoka E. Survival of microorganisms on complete dentures following ultrasonic cleaning combined with immersion in peroxide-based cleanser solution. Gerodontology. 31 (2014) 202-209

- Nobile CJ, Mitchell AP. Microbial biofilms: e pluribus unum. Curr Biol. 17 (2007) 349-353.

- $\quad$ Nobile CJ, Nett JE, Hernday AD, Homann OR, Deneault JS, Nantel A, Andes DR, Johnson AD, Mitchell AP.Biofilm matrix regulation by Candida albicansZap1.PLoS Biol.7 (2009) 1-15.

- O’Donnell LE, Robertson D, Nile CJ, Cross LJ, Riggio M, Sherriff A, et al. The oral microbiome of denture wearers is influenced by levels of natural dentition. PLoS One 10 (2015).

- O'Donnell LE, Smith K, Williams C, Nile CJ, Lappin DF, Bradshaw D, Lambert M, Robertson DP, Bagg J, Hannah V, Ramage G. Dentures are a Reservoir for Respiratory Pathogens. J Prosthodont. 25 (2016) 99-104.

- $\quad$ Papadiochou S, Polyzois. Hygiene practices in removable prosthodontics: A systematic review. Int J Dent Hygiene. 16 (2018) 179-201.

- Papadiochou S, Emmanouil I, Papadiochos I. Denture adhesives: a systematic review. J Prosthet Dent. 113 (2015) 391- 397.

- Paranhos Hde F, Salles AE, Macedo LD, Silva-Lovato $\mathrm{CH}$, Pagnano VO, Watanabe E. Complete denture biofilm after brushing with specific denture paste, neutral soap and artificial saliva. Braz Dent J. 24 (2013) 47-52

- Passariello C, Di Nardo F, Polimeni A, Di Nardo D, Testarelli L. Probiotic Streptococcus salivarius Reduces Symptoms of Denture Stomatitis and Oral Colonization by Candida albicans. Appl. Sci. 10 (2020) 3002 
- Pellizzaro D, Polyzois G, Machado AL, Giampaolo ET, Sanitá PV, Vergani CE. Effectiveness of mechanical brushing with different denture cleansing agents in reducing in vitro Candida albicans biofilm viability. Braz Dent J. 23 (2012) 547-54.

- Pereira CA, Toledo BC, Santos CT, Pereira Costa AC, Back-Brito GN, Kaminagakura E, et al. Opportu nistic microorganisms in individuals with lesions of denture stomatitis. Diagnostic microbiology and infectious disease. 76 (2013) 419-24.

- $\quad$ Pereira-Cenci T, Del BelCury AA, Crielaard W, Ten Cate JM. Development of Candida-associated denture stomatitis: new insights. J Appl Oral Sci. 16 (2008) 86-94.

- $\quad$ Pradies G, Sanz I, Evans O, Martnez F, Sanz M. Clinical study comparing the efficacy of two denture adhesives in complete denture patients. Int J Prosthodont. 22 (2009) 361-367.

- Przybyłowska D, Mierzwińska-Nastalska E, Rubinsztajn R, Chazan R, Rolski D, Swoboda-Kopeć E: Influence of denture plaque biofilm on oral mucosal membrane in patients with chronic obstructive pulmonary disease. AdvExp Med Biol. 839 (2015) 25-30.

- Ramage G, Vandewalle K, Wickes BL, López-Ribot JL.Characteristics of biofilm formation by Candida albicans.RevIberoamMicol. 18 (2001)163-70.

- Ribeiro DG, AC Pavarina, LN Dovigo, MacHado AL, Giampaolo ET, Vergani CE. Prevalence of Candida spp. associated with bacteria species on complete dentures. Gerodontology, 2012 a.

- Ribeiro DG, Pavarina AC, Dovigo LN, et al. Photodynamic inactivation of microorganisms present on complete dentures. A clinical investigation. Photodynamic disinfection of complete dentures. Lasers Med Sci. 2 (2012) 61-168.

- Richard ML, Nobile CJ, Bruno VM, Mitchell AP. Candida albicans biofilm-defective mutants.Eukaryot Cell. 8 (2005) 1493-502.

- Sahariah P, Masson M. Antimicrobial chitosan and chitosan derivatives: a review of the structure-activity relationship. Biomacromolecules 18 (2017) 3846-68.

- $\quad$ Singh R, Shitiz K, Singh A. Chitin and chitosan: biopolymers for wound management. Int Wound J 14 (2017) 276-89.

- $\quad$ Salles MM, Badaró MM, Arruda CNF, Leite VMF, Silva CHL, Watanabe E, et al. Antimicrobial activity of complete denture cleanser solutions based on sodium hypochlorite and Ricinuscommunis - a randomized clinical study. J Appl Oral Sci. 23 (2015) 637-42.
- Samaranayake LP, W Keung Leung, L. Jin, Oral mucosal fungal infections, Periodontology 2009.

- Santana IL, Gonçalves LM, de Vasconcellos AA, da Silva WJ, Cury JA, Del BelCury AA. Dietary carbohydrates modulate Candida albicans biofilm development on the denture surface. PLoS One.8 (2013).

- Srinivasan M, Gulabani M. A microbiological evaluation of the use of denture cleansers in combination with an oral rinse in complete denture patients. Indian J Dent Res. 21 (2010) 353-356.

- Takamiya AS, Monteiro DR, Gorup LF, Silva EA, de Camargo ER, Gomes-Filho JE, Penha de Oliveira SH, Barbosa DB.Biocompatible silver nanoparticles incorporated in acrylic resin for dental application inhibit Candida albicans biofilm. Materials Science \& Engineering C 118 (2021) 111341 1-8.

- Varlam DE, Siddiq MM, Parton LA, Russmann H..Apoptosis contributes to amphotericin B-inducednephrotoxicity. Antimicrob Agents Chemother. 45 (2001) 679-685.

- Verhaeghe TV, Wyatt CC, Mostafa NZ. The effect of overnight storage conditions on complete denture colonization by Candida albicans and dimensional stability: A systematic review. J Prosthet Dent 124 (2020) 176-82).

- Verlee A, Mincke S, Stevens CV. Recent developments in antibacterial and antifungal chitosan and its derivatives. Carbohydr Polym 164 (2017) 268-83.

- Wade WG. The oral microbiome in health and disease. Pharmacological Research: the official journal of the Italian PharmacologicalSociety 69 (2013) 137-43.

- Walsh T, Riley P, Veitz-Keenan A. Interventions for managing denture stomatitis. Cochrane Datab. System. Rev. 2015.

- Yeater KM, Chandra J, Cheng G, Mukherjee PK, Zhao X, Rodriguez-Zas SL, Kwast KE, Ghannoum MA, Hoyer LL. Temporal analysis of Candida albicansgene expression during biofilm development.Microbiology. 153 (2007) 2373-85.

- Zainal M, Zain NM, Amin IM, Ahmad VN. The antimicrobial and antibiofilm properties of allicin against Candida albicans and Staphylococcus aureus - A therapeutic potential for denture stomatitis. Saudi Dental Journal (2020) $1-7$.

- Zhang H, D. Hua, C. Huang, S.K. Samal, R. Xiong, F. Sauvage, et al., Materials and technologies to combat counterfeiting of pharmaceuticals: current and future problem tackling, Adv. Mater. 32 (2020). 